\title{
O PROGRAMA DE GUARDA RESPONSÁVEL DE ANIMAIS DE CURITIBA E SUA APLICAÇÃO NO ACANTONAMENTO ECOLÓGICO
}

\author{
The Program Manager of Guard Animals in Curitiba and your application in Cantonment \\ Ecological
}

\author{
Merjorie Eloise Dzieciol ${ }^{1}$, Cláudia Regina Bosa ${ }^{2}$ \\ ${ }^{1}$ Licenciatura em Ciências Biológicas - PUC/PR. \\ dzieciol.merjorie@gmail.com \\ ${ }^{2}$ Depto. de Pesquisa e Conservação da Fauna-SMMA \\ crbosa@hotmail.com
}

\section{RESUMO}

Muitos animais são abandonados e sofrem maus tratos. No Brasil e no mundo existem programas de defesa de animais. Este trabalho teve como objetivo analisar a eficácia do Programa da Rede de Defesa e Proteção Animal de Curitiba e verificar se depois de realizadas as atividades de teatro de fantoches e entrega da cartilha educativa, através da aplicação de questionários pré e pós teste as crianças que participaram do Acantonamento Ecológico, assimilaram a importância da guarda responsável. Os questionários foram aplicados a 126 alunos da Rede Municipal de Ensino de Curitiba. Ao responder o questionário pré teste sobre o que entendiam por guarda responsável 59 alunos dos 93 analisados nesta etapa (os que possuem animal de estimação) responderam que era a qualidade de vida do animal. Após as atividades, no questionário pós teste com a participação dos 126 alunos, 118 responderam corretamente o que é guarda responsável e bem estar animal. Com relação à microchipagem e cadastramento apenas 90 alunos compreenderam como se faz, mostrando assim, que a abordagem para este tema específico deve ser reavaliada. Nos demais aspectos a abordagem utilizada pelo programa mostrou-se eficiente e capaz de sensibilizar os alunos para a compreensão que os animais de estimação merecem respeito e qualidade de vida. Palavras-chave: Abandono de animais, Educação Ambiental, microchipagem.

\section{ABSTRACT}

Many animals are abandoned and maltreated. In Brazil and the world there are animals of defense programs. This study aimed to examine the effectiveness of the Program of Responsible Animal Guardian of the City of Curitiba and see if after carrying out activities of marionettes and delivery of the booklet through the use of questionnaires before and after testing the children participated in the Ecological Cantonment, assimilated the importance of responsible ownership. Questionnaires were administered to 126 students. In answering the pretest questionnaire on what they understood by responsible pet ownership 59 of the 93 students analyzed at this stage (the ones with pet) responded that was quality of life of the animal. After the activities in the posttest questionnaire with the participation of 126 students, 118 responded correctly on what responsible pet ownership and animal welfare. With respect to microchip and register only 90 students understood how to do it, demonstrating that the approach to this particular topic should be reconsidered. In other aspects the approach used by the program proved to be efficient and able to sensitize students to the understanding that pets deserve respect and quality of life. 


\section{DZIECIOL \& BOSA, vol.(4), ${ }^{\circ}$ 4, p. 877-886, 2011. Monografias Ambientais (e-ISSN: 2236-1308)}

REMOA

Keywords: animal abandonment, Environmental Education, microchip. INTRODUÇÃO

Desde os tempos pré-históricos os animais acompanham o ser humano. A domesticação começou com os homens primitivos para suprir necessidades religiosas, de companhia, alimentação e vestimentas. $\mathrm{O}$ homem primitivo, por instinto, estava mais próximo dos animais, como: bovinos, equinos e lobos por serem mais sociáveis, mansos e de boa adaptação com o ambiente, foram então, facilmente domesticados (AZEVEDO, 2002).

Segundo AZEVEDO (2002), no ano de 1886 DUERST sugeriu a hipótese que a domesticação ocorreu por volta de 7.000 anos antes da era cristã, há indícios de que os babilônios já possuíam animais domésticos há cerca de 5.000 anos a.P. A convivência do homem com o cão vem desde o tempo da "pedra polida" e com o gato, há pelo menos 4.000 anos a.P. Não se pode negar a importância e influência dos animais, no progresso da civilização humana, afinal, foram e são eles que suprem a necessidade de alimentação do homem e durante anos, fizeram o transporte de várias mercadorias, lavravam terras, seus pelos e penas serviam de agasalho. Já aqueles que não eram usados para trabalho ou para as necessidades básicas, serviam como divertimento e consequentemente criavam vínculos de afetividade.

Seres humanos e animais apresentam alguns aspectos em comum: a necessidade de alimentação e água, abrigo e companhia, liberdade de movimentos e de não sentir dor ou sofrimento. Inicialmente, o bem estar animal era tratado como proteção contra crueldades e posteriormente a dar condições de obter o bem estar. O qual consiste em desfrutar de uma boa saúde mental e física para que haja harmonia no ambiente em que se vive (SILVANO, et al., 2010).

O bem estar animal está relacionado com necessidades, como: liberdade, felicidade, competição, controle, sensações, estresse, dor, sofrimento, saúde, entre outros. Quando existe a precariedade de bem estar, são percebidos efeitos fisiológicos. Mensurações referentes ao comportamento do animal, também são relevantes para o bem estar, por exemplo, quando um animal se esquiva ou foge de um objeto ou evento, nos mostra seus sentimentos e consequentemente sobre seu bem estar (BROON \& MOLENTO, 2004).

A saúde física e mental dos animais, essencialmente daqueles utilizados em experimentos depende de um espaço adequado ao tamanho do animal, bem como água e comida específicos para cada espécie, temperatura constante e luz artificial adequada, deste modo, pode-se reduzir o sofrimento e o número de animais utilizados em pesquisas (SCHNAIDER \& SOUZA, 2003).

Os seres humanos, possuem sentimentos como: raiva, frustração, alegria, tristeza, amor, entre outros, mas e os animais podem sentir? Ainda não há convicção sobre o assunto, uma vez que não existe uma resposta clara sobre isto, portanto, os seres humanos tem o dever de tratar os animais como se pudessem sentir. Tal fato acaba tornando-os prováveis seres sencientes, ou seja, seres que sentem ou tem sensações (MOLENTO, 2006).

Por muitos anos a Prefeitura Municipal de Curitiba usou meios indiscriminados para controlar a população de cães e gatos das ruas, a prova disso foi que em apenas um ano cerca de 18.000 animais foram eliminados (processo interrompido desde 2005) a intenção era diminuir o número destes animais nas ruas para evitar a proliferação de doenças principalmente a hidrofobia (raiva), protocolo sugerido pela Organização Mundial da Saúde (OMS). Mas, segundo a Declaração Universal dos Direitos dos Animais, decretada em uma assembléia da UNESCO realizada em Bruxelas no ano de 1978 e segundo os estudos mais recentes da OMS (em alguns países a eliminação de cães chegou a $15 \%$ de sua população), conclui-se que esta ação foi totalmente 


\section{DZIECIOL \& BOSA, vol.(4), ${ }^{\circ}$ 4, p. 877-886, 2011. Monografias Ambientais (e-ISSN: 2236-1308)}

REMOA

ineficaz, pois a taxa de eliminação era superada rapidamente pela taxa de reposição (TRAAD et al., 2009).

Com base nestes dados, a Prefeitura Municipal de Curitiba criou o Programa Rede de Defesa e Proteção Animal da Cidade de Curitiba, o qual tem como objetivos educar e sensibilizar a população para que tenha uma guarda responsável (uma das práticas para promover o bem estar). As violências contra os animais são constantes em meio à sociedade dos que se julgam "animais racionais", mas desconhecem e ignoram a dignidade animal na qualidade de ser que sente, sofre e possui necessidades e direitos (SANTANA, 2004).

A guarda responsável deve ser tratada com a importância que merece, pois é uma das mais urgentes construções jurídicas do direito ambiental. Houve um grande crescimento da urbanização, as pessoas passaram a adquirir hábitos coletivos, como por exemplo, a criação de animais domésticos. Consequentemente, acabam estes sendo um entretenimento e constituem fortes laços de afetividade. Porém, nem sempre ocorre essa relação familiar entre seres humanos e animais domésticos. É muito comum encontrar arbitrariedades praticadas pelo ser humano que comprometem a dignidade e o direito de bem estar desses seres, cuja sobrevivência depende totalmente de seu guardião, muitos sofrem abusos, maus tratos e crueldade (LEVAl, 2007). Alguns donos adestram seus animais para que se tornem ferozes usando-os como arma, outros acabam abandonando-os nas ruas, o que é um grande problema, tanto para o animal que sofre pela precariedade de cuidados, quanto para toda a sociedade (SANTANA \& OLIVEIRA, 2004).

A legislação brasileira é clara quanto a maus tratos aos animais, segundo a Lei Federal $n^{\circ}$ 9.605/1998 - Lei de Crimes Ambientais, devidamente regulamentada pelo decreto 3.179 em 21/09/1999, no Artigo 32, refere-se a aquele que praticar ato de abuso, mau trato, ferir ou mutilar animais silvestres, domésticos ou domesticados, nativos ou exóticos, pena de detenção de três meses a um ano, e multa de $\mathrm{R} \$ 500,00$ a $\mathrm{R} \$ 2.000,00$. (Lei 9.605, 1998 art. 32). Em 2003, durante a primeira reunião Latino-Americana de especialistas em posse responsável de animais de companhia e controle de populações caninas, a guarda responsável foi constituída como uma condição onde o guardião de um animal aceita e se compromete a assumir todos os deveres centrados no atendimento das necessidades deste (SOUZA, 2003).

A divulgação de informações sobre a sensibilização das pessoas em relação ao bem estar dos animais e a guarda responsável é imprescindível para que não haja mais casos de abusos e crueldade com animais. (ROLLIN et al., 2010). Há algum tempo, quando os animais fugiam da casa de seus donos, ou até mesmo, quando eram abandonados, a chance de serem encontrados era mínima, por inúmeros fatores e estes acabavam nas ruas em péssimas condições.

Hoje, essa perspectiva vem mudando devido ao programa de microchipagem de cães, gatos e cavalos, onde após o cadastramento no Sistema de Identificação Animal (SIA) realizado através do site www.protecaoanimal.curitiba.pr.gov.br, da Prefeitura Municipal de Curitiba, o animal recebe um chip de aplicação subcutânea que corresponde a um número único no mundo todo. Este número é decodificado com aparelho leitor e a sua identificação é feita pela correspondência do número do chip com o registrado no cadastro do site. Há também um projeto de unidade móvel de esterilização e educação para a guarda responsável, onde a castração e a microchipagem são uma parceria entre a Prefeitura Municipal de Curitiba e a Universidade Federal do Paraná para solucionar parte do problema, tal é realizado em diversos pontos da cidade, principalmente nas áreas carentes. O custo acessível do microchip é mais um ponto positivo para que a sociedade adote esta medida.

Em diversas partes do mundo existem Organizações não Governamentais (ONGs) que trabalham a guarda responsável, dentre elas as mais conhecidas são: a Sociedade Mundial de Proteção Animal 


\section{DZIECIOL \& BOSA, vol.(4), ${ }^{\circ}$ 4, p. 877-886, 2011. Monografias Ambientais (e-ISSN: 2236-1308)}

REMOA

(WSPA) e a União Internacional Protetora dos Animais (UIPA), as quais fazem um trabalho em conjunto com o governo de vários países, inclusive o Brasil, para a sensibilização da sociedade perante a importância do tema, além do incentivo para adoção de animais abandonados, educação para toda a sociedade em relação a guarda responsável e bem estar, programas de castração, não aquisição de animais silvestres, entre outros. No Brasil várias cidades já adotaram o programa de guarda responsável e no estado do Paraná as cidades de Londrina, Cascavel e toda a região metropolitana de Curitiba.

O presente trabalho teve como objetivo analisar se as informações contidas no Programa da Rede de Defesa e Proteção Animal da Prefeitura Municipal de Curitiba trabalhadas com o público que participa dos Acantonamentos Ecológicos tem efeitos positivos na sensibilização destes, através da realização de palestras e teatros de fantoches sobre o tema.

\section{MATERIAL E MÉTODOS}

O trabalho foi realizado na Casa de Acantonamento Ecológico, localizado em uma área anexa ao Zoológico Municipal de Curitiba - Paraná. Participaram da pesquisa quatro escolas municipais da rede de ensino de Curitiba. Todos os alunos envolvidos pertenciam ao 50ano do ensino fundamental, com idade entre 9 e 11 anos. Estes passaram um final de semana, inclusive pernoite, realizando diversas atividades de Educação Ambiental na Casa de Acantonamento, tais como: pomar, horta, trilha (diurna e noturna), jogos lúdicos, cerimonial do fogo, palestras, teatro de fantoches (um sobre civismo e outro sobre guarda responsável de animais) entre outras atividades, nas quais puderam vivenciar a experiência do contato direto e ativo com a natureza.

Foram elaborados dois questionários: um denominado de pré teste e outro pós teste. 0 primeiro foi aplicado uma semana antes do acantonamento ecológico na escola de origem. $O$ trabalho foi aprovado pelo comitê de ética e pesquisa (CEP) da Pontifícia Universidade Católica do Paraná (PUC-Pr). Todos os pais ou responsáveis dos alunos participantes tomaram ciência do conteúdo e tema abordado na pesquisa através do Termo de Consentimento Livre e Esclarecido (TCLE).

No Acantonamento Ecológico os alunos participaram da atividade de teatro de fantoches sobre guarda responsável de animais, realizado com o auxilio de integrantes da equipe do acantonamento. Este teatro abordou o tema de abandono, maus-tratos e cuidados como vacinação, higiene e microchipagem.

Após a apresentação do teatro, foi realizada uma conversa para a explicação do tema abordado e realizada a apresentação da cartilha educativa "Animal de estimação... não e brinquedo não". Esta cartilha foi desenvolvida pela equipe de Educação Ambiental do Zoológico Municipal de Curitiba e está disponível para ser baixada no site do Programa de Proteção Animal desta cidade. Em seguida, foi aplicado o questionário pós teste. Foram respondidos 126 questionários. Os dados obtidos foram tabulados e apresentados em forma de histogramas de frequência.

\section{RESULTADOS E DISCUSSÃO}

Os resultados observados no questionário pré teste estão na Fig. 1.

Na Fig. 1-A, 93 alunos responderam que possuiam algum tipo de animal de estimação. Desta forma, nas tabulações do questionário pré teste, 33 questionários (alunos sem animais de estimação) foram desconsiderados. Com relação a que tipo de animal de estimação possuem (Fig. 
1-B) 82 possuem cachorros, 18 gatos e 16 outros tipos de animais (jabutis, peixes, aranhas e aves). Esta questão era de múltipla escolha, por este motivo, o total ultrapassa os noventa e três questionários analisados. Destes alunos, 36 tem apenas um animal, 24 dois, 16 três, 17 mais de três animais (Fig. 1-C).

$\mathrm{Na}$ Fig 1-D percebe-se que a maioria dos animais recebe cuidados de familiares do aluno e não diretamente destes. Com relação aos cuidados com a saúde do animal 91 crianças responderam ser importante e apenas 2 responderam que não (Fig 1-E), mostrando que a maioria tem consciência da importância dos cuidados a serem tomados com o animal (mesmo antes das atividades de sensibilização). Na Fig. 1-F 79 alunos alegaram que vão a procura de seus animais quando estes fogem e 14 responderam que esperam em casa e se ainda assim o animal não voltar, ninguém vai procurá-lo.

Na Fig 1-G 59 alunos responderam que Guarda responsável de animais é a qualidade de vida do animal, como: dar banho, comida, vacinas, entre outros e 34 alunos responderam não saber nada sobre o assunto. Vale salientar que as escolas analisadas apresentam perfil sócio-econômico bastante similar e que duas delas já haviam passado, antes do acantonamento, pelo trabalho do teatro e apresentação da cartilha, isto ajuda a explicar, os conhecimentos demonstrados sobre o assunto abordado.Com relação a acreditar que os animais podem sofrer, 91 alunos responderam que sim e apenas 2 acreditam que animais não sofrem (Fig 1-H). 
DZIECIOL \& BOSA, vol.(4), ${ }^{\circ} 4$, p. 877-886, 2011.

Monografias Ambientais (e-ISSN: 2236-1308)

REMOA
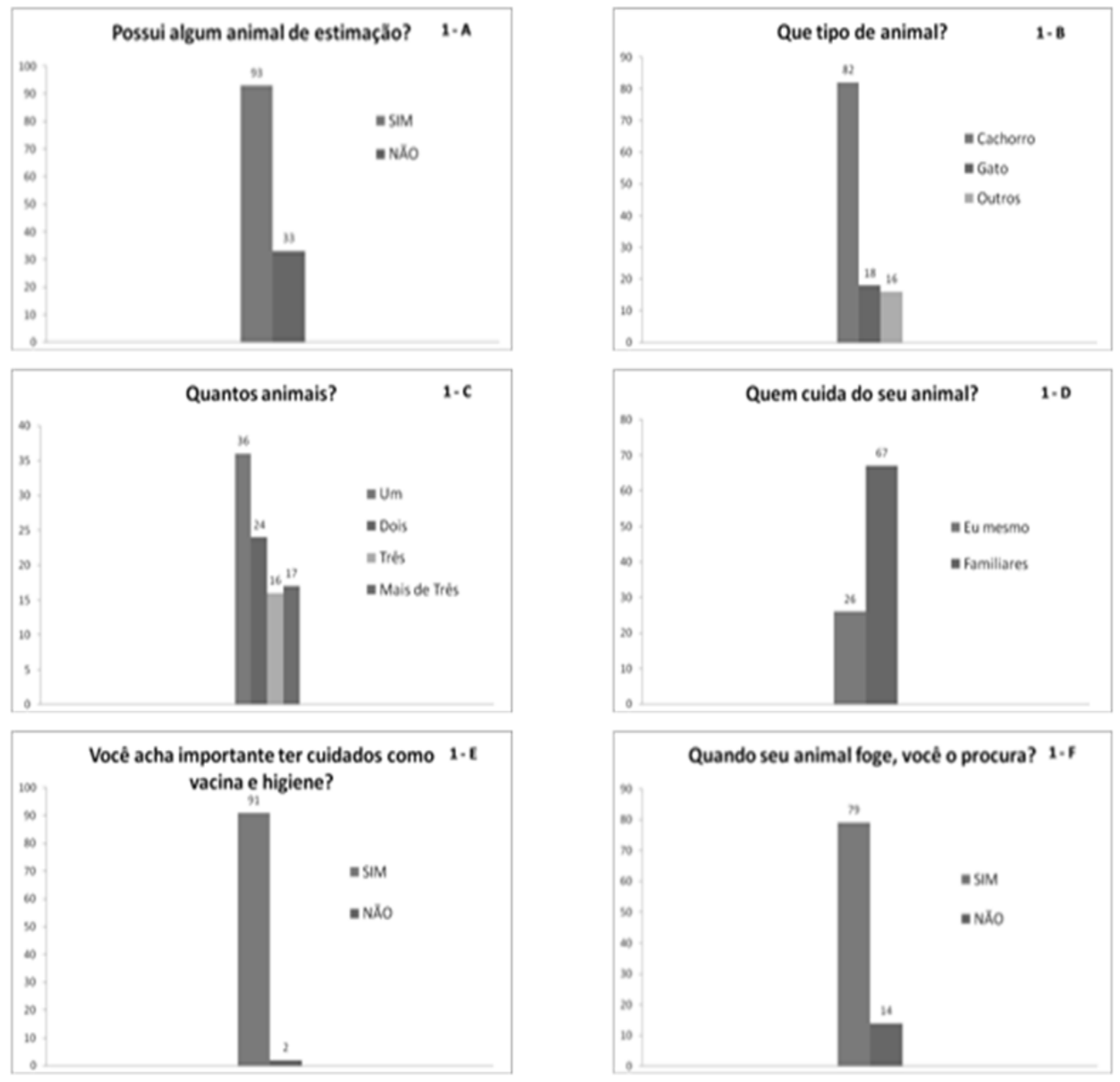

O que você entende por guarda responsável e bem estar animal?

Você acredita que os animais sofrem? 1-H
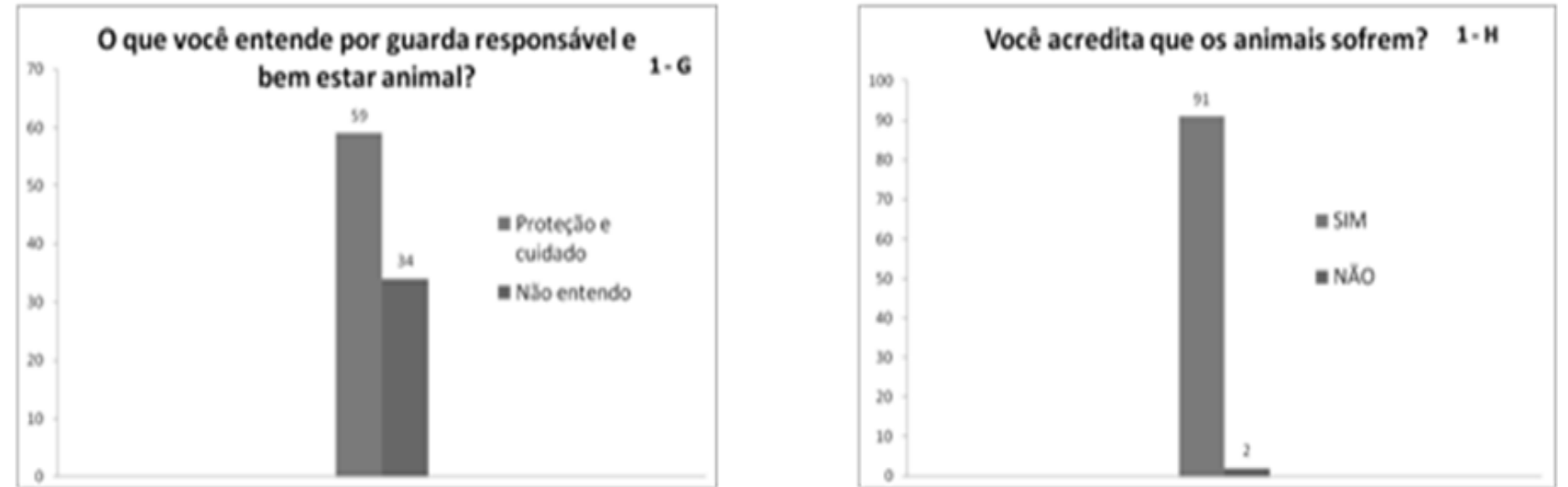

Fig. 1. Resultados obtidos com a aplicação do questionário pré teste. 


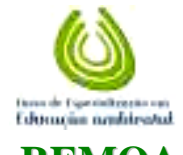

DZIECIOL \& BOSA, vol.(4), ${ }^{\circ} 4$, p. 877-886, 2011. Monografias Ambientais

(e-ISSN: 2236-1308)

REMOA

Após realização das atividades propostas no item metodologia, foi aplicado o questionário pós teste e os resultados observados estão na Fig 2.

Nesta etapa os 126 questionários foram tabulados, pois mesmo as crianças que não possuem um animal de estimação, podem vir a adquirir um algum dia, desta forma, ela já estará sensibilizada de como deverá proceder.

Na Fig 2-A 118 alunos responderam que guarda responsável é dar qualidade de vida ao animal e apenas 8 responderam não compreender do que se trata. Quando indagados sobre a melhor forma de identificar o animal de estimação 122 alunos declaram que seria através do microchip e apenas 4 responderam que somente uma coleira seria suficiente (Fig 2-B). A terceira questão foi referente à microchipagem e ao cadastramento dos animais, 90 alunos responderam que sabem como fazer os procedimentos e 36 alunos que não sabem (Fig 2-C).

Na Fig 2-D os alunos responderam, novamente, se acreditam que os animais podem sofrer, todos responderam que sim. Dos 126 alunos que responderam ao questionário pós teste 124 alegam que colocariam um microchip em seu animal e apenas 2 alunos disseram que não o fariam (Fig 2 E). Na Fig 2-F todos responderam que Guarda responsável é a qualidade de vida do animal, como: dar banho, comida, vacina, carinho, não mal tratar e muito menos abandonar 


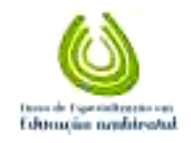

DZIECIOL \& BOSA, vol.(4), ${ }^{\circ} 4$, p. 877-886, 2011.

REMOA Monografias Ambientais

(e-ISSN: 2236-1308)
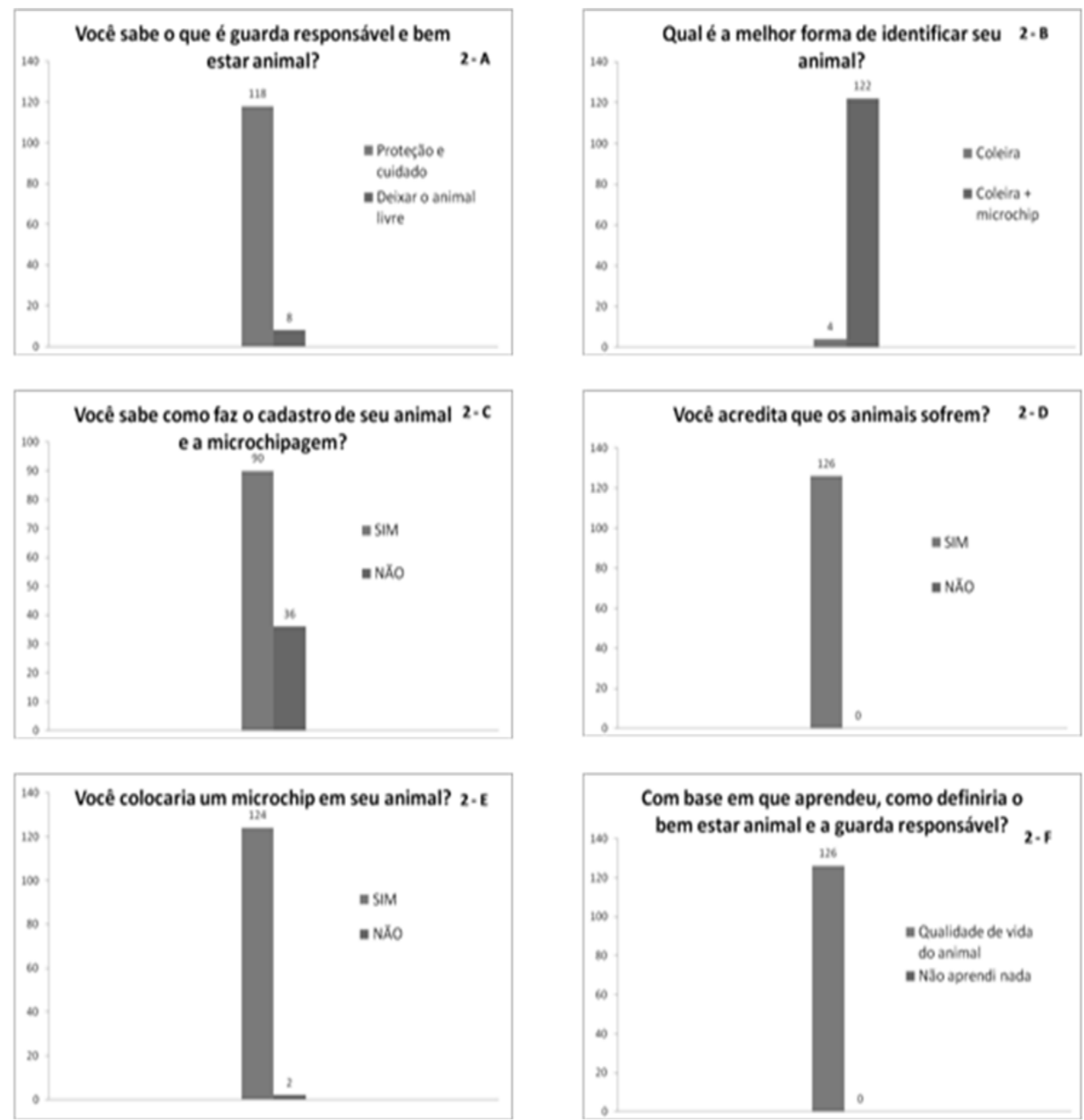

Fig. 2. Resultados obtidos com a aplicação do questionário pós teste.

É muito comum as famílias possuírem animais de estimação, porém muitas vezes por consumismo outras por vontades momentâneas. Quando o animal é adquirido por impulso acarreta uma série de problemas, pois estes acabam descartados nas ruas como objetos (SANTANA \& OLIVEIRA, 2004). Os guardiões só tomam consciência das responsabilidades que um animal traz após acabar a euforia, é ai que surge o grande problema, pois além das obrigações necessárias para manter o bem estar do animal, muitas vezes, as pessoas não pensam que um animal pode viver anos e consequentemente os gastos relacionados a eles também aumentam.

Uma das soluções para este problema é a educação, nela pode-se desenvolver ações de sensibilização e conscientização à toda a população, principalmente às crianças, sobre a responsabilidade da guarda e a preservação ao que chamamos de fauna urbana (TRAAD et al., 2009). Tal solução deve ser feita pelo método humanitário que além das campanhas educacionais 
sobre a guarda responsável, visa a ajuda do Poder Público através da criação de leis para proteger os animais e punir aqueles que os ferem ou abandonam e também programas de vacinação e castração (SANTANA \& OLIVEIRA. 2004).

Os trabalhos que utilizaram questionários para avaliar a eficiência de um programa de guarda responsável não contemplam situações com crianças do ensino fundamental e muito menos a microchipagem e o cadastramento. A situação mais próxima é observada em um programa denominado "Para Viver de Bem com os Bichos" (PVBB), implantado pelo Centro de Controle de Zoonoses de São Paulo aplicado à professores (VIARO et al., 2010). Este trabalho consiste em um curso de capacitação aos professores realizado pelo Centro de Controle de Zoonoses. Em uma primeira etapa foram aplicados questionários aos professores para avaliar o aprendizado dos mesmos referente ao tema abordado no curso, posteriomente foi analisada a atividade exercida nas Unidades Educacionais de cada professor. Conclui-se que na primeira etapa o conhecimento prévio sobre a guarda responsável foi insuficiente quanto a proteção, cuidados, zoonoses e controle reprodutivo. Na segunda etapa os professores mostraram ter adquido o conhecimento sobre estes temas porém foi ineficaz para garantir a ação da multiplicação de informações nas Unidades Educacionais (VIARO et al., 2010).

Na Costa Rica há um programa de controle populacional chamado "Educação Humanitária nas Escolas Públicas: Respeito a Todas as Formas de Vida", o qual foi considerado modelo pela Organização Pan - Americana de Saúde (OPAS) este programa teve necessidade de existir devido a população canina da localidade ser de 1.280 .000 (um milhão e duzentos e oitenta mil), e destes mais de $30 \%$ vivendo nas ruas. Este programa consiste em diversas ações por todas as escolas do país criando uma cultura de respeito com os animais e idealizando a guarda responsável, além do trabalho feito nas mídias (SANTANA \& OLIVEIRA 2004).

É possivel observar, com base nos dois projetos citados, que o primordial é que a informação chegue primeiro às escolas é nisso que se baseia a Prefeitura Municipal de Curitiba, porém com um diferencial o cadastramento e a microchipagem. A divulgação da informação é vital para o sucesso do programa, as crianças que participaram do Acantonamento Ecológico, receberam tal informação e como foi verificado, a grande maioria conseguiu compreender os temas abordados. Neste trabalho observou-se que após a realização das atividades os alunos compreenderam o que é guarda responsável e bem estar animal. Porém, dos 126 alunos que participaram da pesquisa, apenas 90 conseguiram entender como se faz o cadastramento e a microchipagem, portanto deve-se dar mais atenção na abordagem destes durante o teatro e a intervenção realizada.

\section{REFERÊNCIAS BIBLIOGRÁFICAS}

Azevedo, J.G. Domesticação dos animais [Acesso em: 28. abr. 2011]. Bahia. 2002. Disponível em: http://www.ufrb.edu.br/lea/index2.php?option=com docman\&task=doc view\&gid=32\&ltemid= 7

Brasil, Legislação Federal do Brasil - Lei federal de crimes ambientais n 9.605/98 [Acesso em: 25. Jul. 2010]. Brasília, DF; 1998. Disponível em: http://www.planalto.gov.br/ccivil/L9605.htm

Broom, D. M.; Molento, C.F. Bem estar animal: conceito e questões relacionadas. [Acesso em: 04. Mai. 2011]. Curitiba, 2004 - Arquives of Veterinary Science, v.9, n.2, p.1-11- Disponível em: http://www.freewebs.com/hotzel/Molento2004.pdf 
Levai, F. L. Crueldade consentida: a violência humana contra os animais e o papel do ministério público no combate a tortura institucionalizada. [Acesso em 27. Jan. 2011]. São José dos Campos; 2007 - Disponível em: http://terraverdeviva.com.br/crueldadeconsentida.pdf

Molento, C.F. Senciência animal. [Acesso em: 06. Mai. 2011] Conselho Regional de Medicina Veterinária do Paraná, Curitiba; $2006 . \quad$ Disponível em: http://www.labea.ufpr.br/publicacoes/pdf/P\%E1ginas\%20Iniciais\%202\%20Senci\%EAncia.pdf

Rollin, B. (Traduzido por Larissa H. Rüncos e Carla FM Molento) - Dor animal: o que é e porque importa? [Acesso em: 29. 2011]. Curitiba; 2003.2 Disponível http://www.labea.ufpr.br/publicacoes/pdf/2010\%20Bernard\%20Rollin\%20Animal\%20Pain\%20What\%20It\%20ls\%20W hy\%20lt\%20Matters\%20traduzido\%20final.pdf

Santana, L.R.; Oliveira, T. P. - Guarda responsável e dignidade dos animais - [Acesso em: 21. Jul. 2010 ]. Bahia; 2004. Disponível em: http://www.nipeda.direito.ufba.br/guardaresponsaveledgnidadedosaniais.pdf

Santana, H. J. Abolicionismo animal. [Acesso em 21. jul. 2010]. Bahia; 2004. Disponível em: http://www.abolicionismoanimal.org.br/artigos/abolicionismoanimal.pdf

Silvano, D.; Bendas, J. R.; Miranda, M. G.; Pinhão, R.; Mendes-de-Almeida, F.; Labarthe, N. V.; Paiva, J. P. Divulgação dos princípios da guarda responsável: uma vertente possível no trabalho de pesquisa a campo - [ Acesso em: 04. mai. 2011]. Rio de Janeiro, 2010. Revista Eletrônica Novo Enfoque, v. 09, n. 09, p. 64 - 86 . Disponível em: http://www.castelobranco.br/sistema/novoenfoque/files/09/artigos/06.pdf

Souza, M. F. Primeira reunião latino-americana de especialistas em posse de animais de companhia e controle de populações. 2003. Set. 01 a 03. Rio de Janeiro, Brasil, 2003.

Schneider, B. T.; Souza, C. Aspectos éticos da experimentação animal. [Acesso em 06. mai. 2011]. Minas Gerais, 2003 Revista Brasileira Anestesiol 53: 2: $278 \quad$ - $285 . \quad$ Disponível em: http://www.scielo.br/pdf/\%0D/rba/v53n2/v53n2a14.pdf.

Tradd, M. E.; Brasil, L. G.; Bregenski, M. A. et al. -[Acesso em 29. Abr. 2011]. Curitiba, 2009. - Resumo do plano de defesa e proteção animal da Prefeitura Municipal de Curitiba. Disponível em: http://www.protecaoanimal.curitiba.pr.gov.br.

Viaro, O., Santos, B. M., Vasconcellos, A. S.; Pinheiro, R. S. Impacto educativo do modulo cães e gatos do projeto "para viver de bem com os bichos".

[Acesso em: 06. mai. 2011]. São Paulo, 2010 - Revista Veterinária e Zootecnia, dezembro, 17 (4): 502-506. Disponível em: http://www.fmvz.unesp.br/ojs/index.php/rvz/article/view/53/70. 